\title{
A FUNÇÃO SOCIAL DA PROPRIEDADE INTELECTUAL: UM OLHAR DESDE OS CONHECIMENTOS TRADICIONAIS
}

\author{
Francielle Benini Agne Tybusch ${ }^{1}$ \\ Micheli Capuano Irigaray ${ }^{2}$
}

\begin{abstract}
RESUMO
O presente artigo visa refletir sobre a função social da propriedade intelectual, no atual sistema de patentes e das políticas de acesso aos medicamentos. Neste sentido, busca resolver a seguinte questão: É possível afirmar que a função social da propriedade intelectual, no atual sistema de patentes e das políticas de acesso aos medicamentos, tem como elemento norteador os direitos humanos na construção de uma nova base jurídica? Como metodologia foi utilizado o método bibliográfico e documental. Ao final, verificou-se a necessidade de proteção jurídica eficaz, quanto ao reconhecimento da função social da propriedade intelectual, especialmente quando relacionada à indústria farmacêutica.
\end{abstract}

Palavras-chave: Função Social; Propriedade Intelectual; Conhecimentos Tradicionais.

\section{THE SOCIAL FUNCTION OF INTELLECTUAL PROPERTY: A LOOK FROM TRADITIONAL KNOWLEDGE}

\section{ABSTRACT}

This article to reflect on the social function of intellectual property, in the current patent system and policies access to medicines. In this sense, it seeks to solve the following question: Is possible to affirm that the social function of intellectual property, in the current patent system and the policies of access to medicines, is guiding human rights in the construction of a new legal basis? As methodology was used the bibliographic. In the end, was verified the need for effective legal protection, regarding the recognition of the social function of intellectual property, especially when related to the pharmaceutical industry.

Keywords: Social function; Intellectual property; Traditional Knowledge.

\section{INTRODUÇÃO}

\footnotetext{
1 Doutoranda em Direito pela Universidade do Vale do Rio dos Sinos - UNISINOS. Mestre em Direito pela Universidade Federal de Santa Maria - UFSM com bolsa da Fundação de Amparo à Pesquisa do Estado do Rio Grande do Sul, FAPERGS. Bacharel em Direito pela Faculdade Palotina de Santa Maria - FAPAS. Professora da Universidade Regional Integrada do Alto Uruguai e das Missões - URI/SANTIAGO.Membro da equipe técnica da Revista Direitos Emergentes na Sociedade Global da Universidade Federal de Santa Maria. Integrante do Grupo de Pesquisa em Direito da Sociobiodiversidade (GPDS) da Universidade Federal de Santa Maria - UFSM e e do Grupo de Pesquisa em Direito, Risco e Ecocomplexidade da Universidade do Vale do Rio dos Sinos - UNISINOS

${ }^{2}$ Mestre em Direito pela Universidade Federal de Santa Maria, com ênfase em Direitos Emergentes na Sociedade Global, linha de pesquisa Direitos da Sociobiodiversidade e Sustentabilidade., Bacharel em Direito, Especialização em Direito Civil e Direito Constitucional e Ambiental, pela Universidade da Região da Campanha URCAMP. Advogada, inscrita na OAB-RS sob n. 38191. Docente da Universidade da Região da Campanha de 2004 a 2014. Docente da Rede Pública Estadual Curso Técnico em Contabilidade. Integrante dos Grupos de Pesquisa em Direito da Sociobiodiversidade- GPDS e Direito, Marxismo e Meio Ambiente, da Universidade Federal de Santa Maria. E-mail: capgaray@brturbo.com.br
} 
A partir de 1970, começou a se destacar o antagonismo entre meio ambiente e desenvolvimento, colocando em dúvida o atual modelo, marcado pelo avanço tecnológico e pela apropriação dos recursos naturais através da biopirataria. Os países do Sul (social) são elencados como os mais vulneráveis nesse sentido, pelo domínio econômico dos países do Norte e pela grande influência das indústrias farmacêuticas e transnacionais, com grande interesse na exploração da biodiversidade dos países tropicais e pela rica e variada diversidade biológica e cultural.

Assim, a natureza transformada em recurso não tem outra lógica senão a de ser explorada até a sua exaustão. Os maiores beneficiários dessa relação tem sido seguramente as indústrias farmacêuticas e agroquímicas. No que se refere a indústria farmacêutica, é sabido que atualmente os medicamentos prescritos no Norte são produzidas de substâncias originárias do Sul.

Os direitos de propriedade intelectual permitem e legitimam essas formas de apropriação dos conhecimentos indígenas e locais e de apropriação privada de bens fundamentais para a salvaguarda e promoção da saúde pública assentam nas concepções privadas radicadas na ordem jurídica do capitalismo, concepção esta adotada a aplicação do Trips. O presente artigo visa refletir sobre a função social da propriedade intelectual, tendo os direitos humanos como elo norteador na construção de uma nova base jurídica, em oposição ao atual modelo de desenvolvimento baseado na hegemonia de apropriação dos recursos naturais em detrimento da proteção dos conhecimentos tradicionais associados à biodiversidade, dos direitos fundamentais e da vida.

$\mathrm{O}$ artigo busca responder ao longo do trabalho ao seguinte questionamento: É possível afirmar que a função social da propriedade intelectual, no atual sistema de patentes e das políticas de acesso aos medicamentos, tem como elemento norteador os direitos humanos na construção de uma nova base jurídica? No primeiro item temático, realizar-se-á uma abordagem quanto aos conhecimentos tradicionais enquanto propriedade intelectual na contemporaneidade e seus efeitos, e no segundo item, será versado acerca da função social dos conhecimentos tradicionais, como princípio norteador de sua classificação: direitos humanos x propriedade intelectual.

Desta forma, a metodologia e estratégia de ação utilizada para desenvolver este artigo obedecem ao trinômio: Teoria de Base; Procedimento e Técnica. Como Teoria de Base, Vandana Shiva. O método utilizado foi o bibliográfico. Como técnica optou-se pela produção de fichamentos e resumos estendidos. 


\section{CONHECIMENTOS TRADICIONAIS COMO PROPRIEDADE INTELECTUAL NA CONTEMPORANEIDADE}

O conhecimento tradicional é um bem da coletividade, produto coletivo de um aprimoramento trabalhado por gerações, representando práticas associadas aos recursos da natureza, os quais ainda se encontram desprotegidos perante um sistema que somente reconhece direitos de caráter econômico. Nesse contexto emerge a necessidade de reflexão quanto ao atual sistema de proteção à propriedade intelectual, o qual não contempla a proteção aos conhecimentos tradicionais, conforme Gregori (2013, p. 162) a lei de propriedade intelectual brasileira, não justifica a falta de tutela desses conhecimentos, refletindo-se no impasse entre as regras do $\operatorname{Trips}^{3}$, que permite patentes sobre a vida, sem fazer qualquer alusão ao conhecimento tradicional, e a $\mathrm{CDB}^{4}$, que dispõem sobre a garantia da proteção destes conhecimentos.

A prática do colonialismo, aqui definida como apropriação de territórios e seres (de modo geral), parece ainda estar ocorrendo, contudo, com novas facetas e mecanismos políticos mais sofisticados. A apropriação de formas de vida (em um sentido genérico) ainda, de alguma forma, se realiza nos dias de hoje, incorporando "novos selvagens" (termo clássico do colonialismo/cristianismo em seu processo de dominação).

Quinhentos anos depois de Colombo, uma versão secular do mesmo projeto de colonização está em andamento por meio das patentes e dos direitos de propriedade intelectual (DPI). [...] A vacância das terras foi substituída pela vacância de vida e espécies, modificadas pelas novas biotecnologias. O dever de incorporar selvagens ao cristianismo foi substituído pelo dever de incorporar economias locais e nacionais ao mercado global, e incorporar os sistemas não-ocidentais de conhecimento ao reducionismo da ciência e da tecnologia mercantilizada do mundo ocidental (SHIVA, 2001, p. 24).

Shiva, ao longo de sua análise, nos conduz a ideia do processo de colonização como um precedente, e isto fica evidente com o seguinte comentário:

A liberdade que as empresas transnacionais estão reivindicando por meio da proteção aos DPI, no acordo GATT sobre os Direitos de Propriedade Intelectual Relacionados ao Comércio (TRIPS), é a liberdade que os colonizadores europeus usufruíram a partir de

\footnotetext{
${ }^{3}$ Acordo TRIPS presente no Decreto $n^{0}$ 1.355, de 30 de dezembro de 1994. Promulgo a Ata Final que Incorpora os Resultados da Rodada Uruguai de Negociações Comerciais Multilaterais do GATT. Disponível em: <http://www.inpi.gov.br/legislacao-1/27-trips-portugues1.pdf>. Acesso em: 12 de mar. de 2017.

${ }^{4}$ A Convenção sobre diversidade biológica - Decreto Legislativo no 2, de 1994 - aprova o texto da Convenção sobre Diversidade Biológica, assinada durante a Conferência das Nações Unidas sobre Meio Ambiente e Desenvolvimento, realizada na cidade do Rio de Janeiro, no período de 5 a 14 de junho de 1992 . Disponível em: <http://www.mma.gov.br/estruturas/sbf_chm_rbbio/_arquivos/cdbport_72.pdf>. Acesso em 12 de mar. de 2017.
} 
1492. Colombo estabeleceu um precedente quando tratou a licença para conquistar povos não-europeus como um direito natural dos europeus (SHIVA, 2001, p. 24).

Então, o ponto central que parece sobressair desta análise é que o mesmo processo de colonização que, de sua forma, negava a humanidade dos povos colonizados, ocorre, atualmente, pelas políticas que regulamentam o tema contemporaneamente. Trata-se de uma atualização da apropriação "natural" que definia "o povo colonizado como parte da natureza", negando sua autonomia.

Nesse contexto ainda podemos destacar a total desconformidade da lei de propriedade industrial e do Trips, com a CDB, no sentido de que esta, prevê a repartição justa e equitativa dos benefícios decorrentes da exploração comercial dos recursos genéticos e dos conhecimentos entre os países e as comunidades tradicionais. Assim, a lei de patentes para aplicação nos conhecimentos tradicionais associados à biodiversidade, trazem disposições incompatíveis, acentuando-se tais contradições, no aspecto da concessão de patentes, em que o titular terá o direito de propriedade exclusiva, sem que sejam levadas em consideração as disposições da CDB, quanto à perspectiva de que o patenteamento possa assegurar a coletividade a justa e equitativa repartição de benefícios. Gregori (2013, p. 163).

\subsection{Relevância do reconhecimento da proteção dos conhecimentos tradicionais associados à biodiversidade para as comunidades locais}

O conhecimento tradicional associado, segundo Santilli (2005, p. 196) inclui toda informação útil à identificação de princípios ativos de biomoléculas ou características funcionais de células e microrganismos, independentemente da utilização tradicional coincidir ou não com a utilização biotecnológica. Nesse sentido, vamos centrar nosso estudo, no reconhecimento da proteção aos conhecimentos tradicionais associados à biodiversidade sobre a propriedade farmacêutica.

$\mathrm{O}$ acesso a esses conhecimentos das comunidades tradicionais, indígenas e quilombolas, são muito disputados pelas grandes empresas farmacêuticas, as populações detêm o conhecimento mais valioso, de informação quanto a utilização da biodiversidade para fins de cura, da possibilidade da produção de medicamentos para diversos males da humanidade. 
A autora (2005, p. 193) ainda observa que as comunidades tradicionais além de conviverem com a biodiversidade, exercem a etnobiodiversidade ${ }^{5}$, integrando o aspecto cultural das comunidades, sendo passado de geração em geração, no desenvolvimento de informações uteis a identificação de princípios ativos que poderiam demorar anos para serem desenvolvidos pela indústria farmacêutica, ou ate mesmo nem fossem corretamente manipulados. Porém Santilli (2005, p. 197) alerta que o acesso a esse valioso conhecimento tradicional, deve ser precedido do consentimento fundamentado de seus detentores, e sua utilização comercial, deve ser feita mediante mecanismos de repartição de benefícios.

Este conflito entre conhecimento científico e tradicional de conhecimentos é chamado por Boaventura de Sousa Santos (2004) de conhecimentos rivais, isto é, a capacidade que o Norte (social) $^{6}$ tem de negar a validade ou mesmo a existência dos conhecimentos alternativos ao conhecimento científico - conhecimentos populares, indígenas, camponeses - para transformá-los em matéria-prima para o desenvolvimento científico.

Em sua significação, o conhecimento tradicional já denota sua condição coletiva, visto que o saber é transmitido em forma de herança e perpassa por várias gerações. Há responsabilidade de toda a comunidade em dar continuidade àquelas tradições (NEVES; POHL, 2006, p. 342). Por terem conhecimento de incontáveis espécies que ainda não foram sistematizadas, além de possuírem um conhecimento maior acerca da biodiversidade, a comunidade científica passa a olhar com novos olhos a prática dos saberes tradicionais, se apoderando das práticas que foram desenvolvidas.

Nesse sentido Gregori (2013.p. 146) afirma que os conhecimentos tradicionais associados à biodiversidade estão relacionados à inovação, às práticas individuais ou coletivas de povos indígenas ou comunidades locais associadas às propriedades, usos e características da diversidade

\footnotetext{
${ }^{5}$ Etnobiodiversidade é a riqueza da natureza da qual também participa o homem, nomeando-a, classificando-a e domesticando-a (SANTILLI, 2005. p. 193).

${ }^{6}$ De acordo com Boaventura de Sousa Santos e Maria Paula Meneses (2010, p. 19), “o Sul é aqui concebido como um campo de desafios sistêmicos, que procuram reparar os danos e impactos historicamente causados pelo capitalismo na sua relação colonial com o mundo. Esta concepção do Sul sobrepõe-se em parte com o Sul geográfico, o conjunto de países e regiões do mundo que foram submetidos ao colonialismo europeu e que, com exceções como, por exemplo, da Austrália e da Nova Zelândia, não atingiram níveis de desenvolvimento econômico semelhantes ao Norte global (Europa e América do Norte). A sobreposição não é total porque, por um lado, no interior do Norte geográfico classes e grupos sociais muito vastos (trabalhadores, mulheres, indígenas, afrodescendentes, muçulmanos) foram sujeitos à dominação capitalista e colonial, e por outro lado, porque no interior do Sul geográfico houve sempre as 'pequenas Europas', pequenas elites locais que beneficiaram da dominação capitalista e colonial e que depois das independências a exerceram e continuam exercer, por suas próprias mãos, contra classes e grupos subordinados”.
} 
biológica, inseridos nos contextos culturais da comunidade, representando assim criações da mente e do espirito coletivo de um povo, transmitidos e aperfeiçoados ao longo de muitas gerações.

A autora (2013, p. 146) ainda faz referência quanto à proteção dos conhecimentos tradicionais associados à Convenção de Diversidade Biológica, a Declaração do Rio em seu princípio 22 afirma que "as populações indígenas e suas comunidades, bem como outras comunidades locais, têm papel fundamental na gestão do meio ambiente e no desenvolvimento, em virtude de seus conhecimentos e práticas tradicionais, sendo que os Estados devem reconhecer e apoiar de forma apropriada a identidade, cultura e interesses dessas populações e comunidades, bem como habilitá-las a participar efetivamente da promoção do desenvolvimento sustentável”.

Sobre as patentes Araújo (2004, p. 135-136) menciona que a situação das mesmas sobre produtos farmacêuticos pelos procedimentos de processos químicos e de proteção de produtos farmacêuticos, o qual vem sendo objeto de contratos de licença para a transferência de tecnologia, e possibilitando o patenteamento de fármacos sem indicação da origem do recurso biológico e dos conhecimentos utilizados, representando um grave risco de biopirataria, referente ao uso indevido e desautorizado da biodiversidade e dos conhecimentos e práticas de comunidades locais, sendo que tais recursos são transformados pelas grandes corporações e ganham status de produtos ou processos farmacêuticos, cumprindo com os requisitos das patentes de novidade, quanto à atividade inventiva e aplicação industrial.

No Brasil a Lei da Propriedade Industrial n. 9.279, em 14 de maio de 1996 (BRASIL, 2001), tem por objeto regulamentar direitos e obrigações relativas à propriedade industrial, não só as patentes, como também as marcas, dispondo no artigo $8^{\circ}$, que é "patenteável a invenção que atenda aos requisitos de novidade, atividade inventiva e aplicação industrial”, quanto à novidade, atividade inventiva e aplicação industrial, sendo que seu prazo de proteção é de 20 anos, e somente depois de esgotado esse prazo de proteção, a invenção deixa de ser propriedade exclusiva de seu titular e pode ser explorada indistintamente por qualquer pessoa.

Assim configura-se claramente o conflito entre a visão holística socioambiental e a preservação dos conhecimentos tradicionais associados, surgindo à necessidade de um processo de busca de uma (re) aproximação do homem com a natureza, de superação do conflito do substituto plastificado, segundo Ost (1997, p. 29-30) o qual representou um paraíso ecológico de dupla manipulação, de dupla falsificação e consequentemente mais um fracasso do encontro do homem com a natureza, em um contexto em que o próprio homem reduziu a natureza aos seus interesses, para além da racionalidade utilitarista. 
De acordo com esses argumentos, verifica-se que até então há uma prevalência da visão antropocêntrica da natureza, o que Capra (2006, p.25) denomina como ecologia rasa, centralizada no ser humano. Ela vê os seres humanos como situados acima ou fora da natureza, como a fonte de todos os valores. Emprega-se a expressão para referir que a biodiversidade é necessária, ainda que sua valorização se realize somente para benefício do homem.

Neste sentido, relacionando a questão histórica pertinente à propriedade intelectual como questão inserta na crise ambiental - especialmente no âmbito latino-americano -, importante salientar as palavras de Juliana Santilli (2005, p.245) a ideia de crise ambiental advém do modelo de exploração colonial imposto aos países do sul social, o qual persiste na contemporaneidade sob o prisma da mercantilização dos conhecimentos tradicionais: fato que origina novos movimentos sociais em prol da proteção ambiental como um todo.

Assim, podemos observar os efeitos do patenteamento, quanto ao avanço das tecnologias de base biológica, do acesso a medicamentos em conflito com a falta de incentivos em pesquisas públicas, em um cenário onde doenças são negligenciadas, e a globalização dos mercados permite a maior penetração de produtos em todas as partes do globo, isto é, a entrada de medicamentos foi facilitada pelo amplo acesso de consumidores através das novas tecnologias. Ocorre que apesar dos consumidores se tornarem mundiais, os fornecedores de produtos continuaram a serem os mesmos grupos de indústrias com grande poder econômico, refletindo-se em um mercado de produtos de base biológica e suas patentes, de domínio econômico, retirando o acesso de grande parte da população. Esse conflito caracteriza como efeito, uma das maiores violações dos direitos humanos, do não reconhecimento do ser, com sujeito de direito, e nesse caso do direito mais supremo, do direito a vida.

\subsection{Efeitos da propriedade intelectual: uma análise da propriedade industrial frente ao acesso de medicamentos}

Dentre os principais efeitos inerentes ao patenteamento de recursos biológicos, esta o direito de patentes e o fechamento do acesso aos recursos contidos na invenção protegida, como observa Hermitte (2004, p.27) quando objetos biológicos têm seus elementos patenteados, são protegidos por uma exclusividade total, em decorrência disso, os concorrentes não podem ter acesso ao recurso para criar novos produtos. Nesse contexto, emergem aspectos polêmicos, quanto à possibilidade de a patente farmacêutica vir a ser utilizada como um recurso no alcance positivo, a favor da proteção 
do interesse público, quanto ao estímulo e a criatividade científica e ao esforço no desenvolvimento de avanços tecnológicos, em contraposição com o efeito indesejável da elevação dos preços dos medicamentos o que propiciaria um monopólio farmacêutico (MARQUES, 2000).

A atuação dos grandes grupos de fármacos está ligada a um jogo de poder e controle social, de biopolítica ${ }^{7}$, com o incentivo do consumo de medicamentos, tornando-se um imperativo mercadológico na gestão da saúde. (CONSCIENCIA POLÍTICA, 2015). Ainda assim, o estado das patentes em medicamentos, de caráter hegemônico, é corroborado pela prática de indústrias em inserirem-se em comunidades tradicionais e sugar o conhecimento dos membros dessas comunidades, conforme observa Mathias (2015, p.20) as indústrias de biotecnologia contam com uma fonte gratuita de matéria prima, ao explorar o conhecimento dos povos indígenas e comunidades locais, apropriando-se de forma privada de seus conhecimentos passados de geração em geração, para fins de patenteamento.

Nesse contexto o acesso aos medicamentos em termos de patentes de biotecnologia vem sendo negligenciado pelas autoridades do mundo todo, haja vista que o atual sistema permite na sua essência o cerceamento da maioria da população mundial das inovações tecnologias deduzidas do conhecimento dos povos tradicionais e tornadas fonte de lucro imensurável. Assim como a concessão de patentes pipeline fundamenta-se no caráter excepcional dos pressupostos que o compõe, conforme artigos 230 e 231 da Lei de Propriedade Industrial, que relegam a segundo plano o princípio da novidade do objeto a ser patenteado e ampliam a gama de produtos, materiais e substâncias passíveis de apropriação mediante solicitação da carta patente (VELÁZQUEZ; OLIVEIRA; 2014, p. 01).

Em face de tal regramento, bem como da afronta aos princípios de cunho constitucional ligados aos direitos da coletividade e, também, aos que regem o direito às patentes, tramita, perante o Supremo Tribunal Federal, a ação direita de inconstitucionalidade n. 4234, a qual tem como objetivo central extirpar os referidos artigos de nosso ordenamento jurídico e, em consequência, revogar a possibilidade de concessão das patentes de revalidação pelo Instituto Nacional de Propriedade Industrial - INPI ${ }^{8}$ (VELÁZQUEZ; OLIVEIRA; 2014, p. 01).

\footnotetext{
${ }^{7}$ Biopolítica é um campo que permite agregar, aproximar, associar setores da realidade relacionados com a vida, a natureza e o conhecimento, cujas mudanças ao longo do tempo foram provocadas pela indústria, pela ciência e pela tecnologia, que hoje disputam o campo político-econômico mundial. Na obra de Michel Foucault, é o estilo de governo que regulamenta a população através do biopoder (a aplicação e impacto do poder político sobre todos os aspectos da vida humana). (FOUCAULT, 1999).

8 O Instituto Nacional da Propriedade Industrial (INPI) é uma autarquia federal vinculada ao Ministério do Desenvolvimento, Indústria e Comércio Exterior (MDIC), responsável pelo aperfeiçoamento, disseminação e gestão do
} 
Assim, trata-se de um mecanismo que tem como finalidade proporcionar a proteção para produtos e processos, dos inventores nacionais e estrangeiros, de criação já divulgada, mas anteriormente não patenteável. Nesse sentido a Procuradoria Geral da República ajuizou a Ação Direta de Inconstitucionalidade - ADIn 4234 - no Superior Tribunal Federal, em 24 de Abril de 2009, contra os artigos 230 e 231 da Lei $n^{\circ}$ 9279/96, que tratam da regulamentação das patentes Pipeline $^{9}$ (SONEGO, 2012, p. 07).

Esse debate foi iniciado a partir da solicitação feita pela FENAFAR (Federação Nacional dos Farmacêuticos), pela REBRIP (Rede Brasileira pela Integração dos Povos) e ABIA (Agência Brasileira Interdisciplinar de AIDS) junto à Procuradoria Geral da União. Vários são os motivos levantados de inconstitucionalidade das patentes pipeline e questionados na ADIn 4234, como violação ao princípio da novidade absoluta, do direito à saúde, do interesse público, interesse social, do devido processo legal, função social da propriedade, princípio da isonomia, entre outros, sendo que os artigos 230 e 231 da Lei no $9279 / 96$ em questão, permitem a revalidação de patentes de produtos que já se encontram em domínio público, mas que anteriormente não eram protegidos, em detrimento direto ao princípio da novidade. Ao todo foram realizados 1.182 pedidos de patentes Pipeline (SONEGO, 2012, p. 07).

Nesse sentido, o Comitê Intergovernamental, criado inicialmente como comitê provisório, com duração prevista até o ano de 2003, tornou-se definitivo e iniciou suas ações para o estabelecimento de um instrumento jurídico internacional para o tratamento dos conhecimentos tradicionais na seara da propriedade intelectual. Diante de tais considerações, reflete-se quanto à necessidade de uma nova ordem jurídica, de proteção eficaz, no reconhecimento da função social da propriedade intelectual, especialmente a relacionada à indústria farmacêutica, como forma de prevalência da proteção dos conhecimentos tradicionais associados à biodiversidade, dos direitos humanos, dos direitos fundamentais e da própria vida humana.

sistema brasileiro de concessão e garantia de direitos de propriedade intelectual para a indústria. Disponível em: <http://www.inpi.gov.br/>. Acesso em: 12 de mar. de 2017.

${ }^{9}$ As patentes pipeline estão previstas nos artigos 230 e 231 da Lei 9.279/96 - a Lei brasileira de Propriedade Industrial (LPI) - os quais possibilitaram depósitos de patentes em campos tecnológicos para os quais o Brasil não concedia patentes até então (principalmente medicamentos1 e alimentos). As patentes pipeline (ou patentes de revalidação) tiveram um mecanismo de processamento diferente das demais patentes solicitadas no Brasil. O depósito de pedido de patente pelo mecanismo pipeline foi aceito pelo período de um ano, entre maio de 1996 e maio de 1997 e "revalidariam" nacionalmente patentes de medicamentos, alimentos e produtos e processos químico-farmacêuticos concedidos em outros países. Estes pedidos passaram apenas por uma análise formal e seguiram os termos da patente concedida no exterior, não sendo submetido a uma análise técnica dos requisitos de patenteabilidade pelo escritório de patentes brasileiro, o Instituto Nacional de Propriedade Industrial (INPI). Disponível em:<http://www.abiaids.org.br/_img/media/PergResp_PIPELINE_PT.pdf >. Acesso em: 12 de mar. de 2017. 


\section{FUNÇÃO SOCIAL DOS CONHECIMENTOS TRADICIONAIS ASSOCIADOS À BIODIVERSIDADE, COMO PRINCÍPIO NORTEADOR DE SUA CLASSIFICAÇÃO: DIREITOS HUMANOS X PROPRIEDADE INTELECTUAL}

A função social dos conhecimentos tradicionais representa a proteção a vida, a biodiversidade, aos direitos fundamentais, aos direitos humanos, como forma de resistência ao modelo hegemônico da propriedade intelectual, da prevalência do econômico. Nesse enfrentamento do homem com a natureza, podemos observar o processo de separação e de alienação da natureza, e até mesmo de sua artificialização, fazendo referência à necessidade de um processo de busca de uma (re) aproximação do homem com a natureza, de superação do conflito do substituto plastificado, que representou um paraíso ecológico de dupla manipulação, de dupla falsificação e consequentemente mais um fracasso do encontro do homem com a natureza. Assim podemos questionar qual a relação que o homem deve ter com a natureza? Observando-se que o próprio homem reduziu a natureza aos seus interesses, para além da racionalidade utilitarista. (OST, 1997, p. 82).

2.1 A relevância do reconhecimento da função social dos conhecimentos tradicionais: conflitos CDB e TRIPS

Os maiores entraves pertinentes aos conhecimentos tradicionais e sua inter-relação com a propriedade intelectual são causados pelo confronto existente entre Acordo Trips (OMC) e Convenção sobre Diversidade Biológica. Neste sentido, importante referir à lição de Vinícius Garcia Vieira:

As contradições entre os interesses do comércio internacional de biotecnologias e as necessidades de proteção da biodiversidade são produzidas, e simultaneamente produzem interações entre os objetivos colocados na CDB e a finalidade de apropriação individual das produções do intelecto para o comércio, constantes no Trips. No tabuleiro das relações internacionais, caminhos opostos resultam do entrechoque entre o regime de proteção da biodiversidade, em formação, e o regime de propriedade intelectual, em plena força e vigor. No cenário internacional observa-se que os países latino-americanos, inseridos na posição de países do Sul, têm postulado a abertura do regime de propriedade intelectual, sob o modelo Trips, aos objetivos da CDB de conservar a biodiversidade mediante sua utilização dos recursos genéticos e transferir tecnologia, de forma a seguir o caminho de cuidado da biodiversidade, com a construção de espaço para valorização cultural dos conhecimentos dos povos indígenas e comunidades tradicionais. (VIEIRA, 2012, p. 121) 
Observando-se assim, que embora o processo de dominação socioeconômica em face da América Latina estivesse em pleno desenvolvimento, a Convenção sobre Diversidade Biológica (1992) surge como alternativa para resguardar a biodiversidade latino-americana, busca-se evitar a exploração desenfreada existente dos recursos naturais existentes na região. Nesse sentido podemos ainda citar a legislação brasileira na busca por um sistema adequado de proteção da biodiversidade, mas que ainda parece não ter superado a hegemonia econômica e política.

Para Carol Proner, a reivindicação do direito à biodiversidade parece responder a essa demanda por superação de limites, instigando questionamentos para além das respostas possíveis dentro do atual sistema ultraliberal (respostas sistêmicas). A biodiversidade questiona, ao mesmo tempo, o equilíbrio ambiental, social, animal, populacional, cultural, sustentável em todos os tempos, unindo passado, presente e futuro (gerações futuras). Por conta desse potencial argumentativo e emancipatório, sua afirmação como direito humano encontra resistências de primeira ordem no contexto da globalização econômica (2007, p. 74-75).

Dentre as principais inovações da lei 13.123/2015, ao revogar a Medida Provisória $n^{\circ} 2.186$ 16/ 2001, foram quanto à regulamentação do art. 225 da Constituição Federal, especificamente do inciso II do $\S 1^{\circ}$, que estatui o dever do Poder Público em preservar a diversidade e a integridade do patrimônio genético do País e fiscalizar as entidades dedicadas à pesquisa e manipulação do material genético, além de regulamentar o seu $\S 4^{\circ}$, que, ao tutelar os biomas nacionais, condicionando o seu uso à lei, dentro de condições que assegurem a preservação do meio ambiente, inclusive quanto ao uso dos recursos naturais, estabelecendo ainda a competência da União para a gestão, o controle e a fiscalização das atividades que regulamenta. (TÁVORA, 2015, p. 82)

Assim, a lei brasileira estabelece a natureza coletiva desse conhecimento, ainda que apenas um membro do povo ou da comunidade em questão o detenha. $\mathrm{O}$ acesso a esse conhecimento é condicionado ao consentimento prévio informado de seus detentores, ressalvados o intercâmbio e a difusão desses conhecimentos entre os próprios detentores e o acesso a conhecimento tradicional associado de origem não identificável, ou seja, de origem ignorada ou difusa. Sendo que o consentimento prévio informado deve ser comprovado mediante assinatura de termo, registro audiovisual, parecer do órgão oficial competente ou adesão na forma de protocolo comunitário, garantindo aos detentores de conhecimento tradicional associado ao patrimônio genético os direitos de: reconhecimento à sua contribuição; indicação da origem do acesso a esse conhecimento; perceber benefícios pela exploração econômica do seu conhecimento; participar do processo de tomada de decisão sobre o acesso ao seu conhecimento e sobre a repartição de benefícios 
decorrentes; usar, vender, conservar, manejar, guardar, produzir, trocar, desenvolver, melhorar livremente produtos e material reprodutivo que contenham patrimônio genético ou conhecimento tradicional associado e ainda resguardando as trocas e o uso tradicionais e espontâneos entre os detentores originais desse conhecimento, enquanto prevê a sua inclusão nos processos de tomada de decisão e no recebimento de benefícios relativos ao uso desse seu patrimônio e de produtos decorrentes do acesso por agentes externos às suas comunidades.

Tais reflexões instigam a averiguação, do recente Marco Legal da Biodiversidade na legislação brasileira, que por meio de algumas permissividades no que se refere ao acesso a recursos genéticos, aferição de lucros e pesquisas científicas derivadas, privilegia a mercantilização de recursos provenientes da biodiversidade brasileira e a utilização dos conhecimentos tradicionais ainda encontram-se em desconformidade com algumas disposições da Convenção sobre Diversidade Biológica. Observando-se que, a referida lei cria mecanismos para facilitar o acesso a recursos genéticos através de variantes que permitem a inexistência de consentimento prévio de determinada comunidade local acerca do conhecimento tradicional a ser utilizado, se a origem daquele conhecimento não for identificável ${ }^{10}$. Salientando-se ainda, que independente de o conhecimento tradicional não ser identificável quanto a sua origem, se a utilização é efetuada tão somente por comunidades tradicionais, é inadmissível que não haja consulta quanto à utilização do conhecimento por grandes corporações que evidentemente farão uso do conhecimento tradicional para a obtenção de lucros.

2.2 Possibilidade do reconhecimento da função social dos conhecimentos tradicionais: uma abordagem dos direitos humanos como elos norteadores da prevalência desse princípio

Quanto à prevalência dos direitos humanos como elos norteadores no reconhecimento da função social dos conhecimentos tradicionais, faz-se necessário refletir sobre a repartição equitativa de benefícios conforme disposto na $\mathrm{CDB}$, artigo $1^{\mathrm{o}}$, quanto à conservação da diversidade biológica, a utilização sustentável de seus componentes e a repartição justa e equitativa dos benefícios derivados da utilização dos recursos genéticos, mediante, inclusive, o acesso adequado aos recursos genéticos e a transferência adequada de tecnologias pertinentes, levando em conta todos os direitos

\footnotetext{
${ }^{10}$ Art. $9^{\circ} \mathrm{O}$ acesso ao conhecimento tradicional associado de origem identificável está condicionado à obtenção do consentimento prévio informado (...) $\S 2^{\underline{0}} \mathrm{O}$ acesso a conhecimento tradicional associado de origem não identificável independe de consentimento prévio informado. (BRASIL. Lei $\mathrm{n}^{\circ}$. 13.123/2015. Disponível em: http://www.planalto.gov.br/ccivil_03/_Ato2015-2018/2015/Lei/L13123.htm - Acesso em: 12 de mar. de 2017).
} 
sobre tais recursos e tecnologias, e mediante financiamento adequado, assim como no artigo $8^{\circ}$ que cada parte contratante deve, na medida do possível e conforme o caso e em conformidade com sua legislação nacional, respeitar, preservar e manter o conhecimento, inovações e práticas das comunidades locais e populações indígenas com estilo de vida tradicionais relevantes à conservação e à utilização sustentável da diversidade biológica e incentivar sua mais ampla aplicação com a aprovação e a participação dos detentores desse conhecimento, inovações e práticas; e encorajar a repartição equitativa dos benefícios oriundos da utilização desse conhecimento, inovações e práticas.

Nesse sentido a Constituição Federal Brasileira, também dispõe sobre a função social como princípio e garantia, inserindo-o nos capítulos dos direitos individuais art. 5, XXII e XXIII art. 170, III da ordem econômica. Evidenciando-se assim a consagração da proteção à propriedade como princípio geral da atividade econômica teve como inspiração o ideal capitalista de preservação da propriedade privada dos bens de produção. Contudo, a sua destinação social, como poder-dever que se impõe ao proprietário, impele o titular desse direito que o exerça tendo em vista os ideais da justiça social e garantia de existência digna para todos.

Com relação à função social da propriedade industrial, parece que recebeu do constituinte um tratamento intermediário, ficando condicionado o cumprimento da função social ao atendimento do interesse social e ao desenvolvimento tecnológico e econômico do País, o constituinte aproveitou-se de conceitos jurídicos também indeterminados, mas de menor grau de abstração e de conteúdo vinculado às suas prescrições, para conferir à Administração a discricionariedade, através de seu órgão técnico-administrativo, o Instituto Nacional da Propriedade Industrial (INPI), definir se aqueles bens de natureza móvel cumprem a finalidade que deles de espera.

Desta forma emerge no aspecto social e de prevalência dos direitos humanos, o reconhecimento da função social das patentes de medicamentos, através de uma nova visão do conceito de propriedade, para além do direito individualista, absoluto, afastando-se da concepção tradicional que consiste em um poder conferido à vontade de seu titular, para exercer, segundo seus próprios interesses, a fruição do bem, o instituto da propriedade intelectual, mais precisamente da propriedade industrial, carece de uma nova leitura em harmonia com o novo paradigma da função social da propriedade. Isto porque, a propriedade intelectual cria, para o seu titular, através dos instrumentos da patente e do registro, direitos morais e patrimoniais exclusivos, que funcionam como recompensa pecuniária, mas a utilização dos bens produzidos pela criatividade humana vincula-se à observância dos interesses sociais, à necessidade de capacitação tecnológica nacional, 
ao progresso e ao bem-estar de toda comunidade. Observando-se assim a necessidade de conciliarse o legítimo interesse do inventor ou do autor, enquanto criador de um bem socialmente útil e economicamente valorável, com a necessidade de torná-lo acessível à sociedade, vislumbrando-se a possibilidade de harmonizar a concepção tradicional de proteção com o paradigma da função social.

\section{CONCLUSÃO}

No atual cenário da biotecnologia, pautado pela exploração econômica dos recursos biológicos e genéticos, emerge o conhecimento tradicional associado à biodiversidade como uma estratégia utilizada pelas indústrias que incorporaram a biotecnologia, tema de grande discussão jurídica frente ao conflito sobre a proteção dos conhecimentos tradicionais associados à biodiversidade e o domínio do poder econômico das grandes empresas transnacionais, detentoras das patentes dos medicamentos a nível global. Destacando-se assim, no contexto internacional, o conflito entre a Convenção sobre Diversidade Biológica (CDB), que afirma a importância de respeitar e de proteger o conhecimento tradicional e o Acordo TRIPS, que no bojo da Organização Mundial do Comércio, encontra-se respaldo por medidas coercitivas de respaldo a propriedade intelectual e ao monopólio de medicamentos.

O sistema atual que tutela a propriedade intelectual não alcança a proteção dos conhecimentos tradicionais, visto que, em virtude de suas características peculiares (transmitidos de geração em geração, disponíveis ao público, muitos deles não tem aplicação industrial direta), tais conhecimentos não preenchem os requisitos necessários para a concessão da patente - modalidade de propriedade intelectual que mais se afina com os conhecimentos tradicionais. Além de os conhecimentos tradicionais não estarem conferidos pela proteção dada pelo sistema de propriedade intelectual, esses conhecimentos estão relegados à condição de matéria-prima, cenário propício para sua exploração econômica no contexto do próprio sistema.

Nesse sentido o presente artigo visou propiciar uma reflexão sobre a função social da propriedade intelectual, no atual sistema de patentes e das políticas de acesso aos medicamentos, tendo os direitos humanos como elos norteadores na construção de uma nova base jurídica, em oposição ao atual modelo de desenvolvimento baseado na hegemonia de apropriação dos recursos naturais em detrimento da proteção dos conhecimentos tradicionais associados à biodiversidade, dos direitos fundamentais e da vida. Abordando o direito de propriedade, enquanto conceito que englobe a função social da propriedade, com a possibilidade de incorporar esse principio na 
construção jurídica do sistema de proteção intelectual, harmonizando-se com interesses sociais, especialmente no que diz respeito às criações intelectuais que proporcionem, diretamente, vantagens sociais, como ocorre com os fármacos, sendo certo que os atuais instrumentos de flexibilização como a licença compulsória, ainda não se mostram suficientes no aspecto social.

Sendo assim, é inegável que o sistema mundial da propriedade industrial apresenta alguns conflitos, beneficiando interesses de grandes corporações, quando, por exemplo, outorga um monopólio de exploração extremamente longo, ou minimiza as possibilidades legislativas de concessão da licença compulsória ou institutos similares. Com efeito, não parece razoável a extensão vintenária da proteção, vez que em tempos atuais dificilmente um empreendimento oferece um retorno financeiro diluído em um lapso temporal tão longo.

Nesse contexto de divergências e conflitos entre direitos humanos e propriedade industrial, foi possível observar a necessidade de uma proteção jurídica eficaz, quanto ao reconhecimento da função social da propriedade intelectual, especialmente a relacionada à indústria farmacêutica, como forma de prevalência da proteção dos conhecimentos tradicionais associados à biodiversidade, dos direitos humanos, dos direitos fundamentais e da própria vida humana.

\section{REFERÊNCIAS}

ARAUJO, Luiz Ernani Bonesso de; FILHO, Airton Guilherme Berge. Propriedade intelectual sobre a diversidade biológica e sobre os conhecimentos tradicionais associados: entre a sustentabilidade e a biopirataria. Revista de Integração Latino-Americana. Ano 1, $\mathrm{n}^{\mathrm{o}}$ 02, MILA, Mestrado em Integração Latino-Americana. Santa Maria: UFSM, 2004.

BRASIL. Constituição Federal. Brasília: Senado Federal, 1988. Disponível em: <http://www.planalto.gov.br/ccivil_03/Constituicao/Constituiçao.htm>. Acesso em: 12 de mar. de 2017.

CAPRA, Fritjof. A teia da vida: uma nova compreensão científica dos sistemas vivos. Trad.

Newton Roberval Eichemberg. São Paulo, Cultrix, 2006.

CONSCIENCIA POLÍTICA: Disponível em:

$<$ http://www.portalconscienciapolitica.com.br/products/industria-farmaceutica-e-medicinatradicional-entre-farmacos-plantas-medicinais-e-fitoterapicos/> acesso em: 12 de mar. de 2017.

GREGORI, Isabel Christine de. Os conhecimentos tradicionais e a biodiversidade: direitos intelectuais coletivos ou monopólio da natureza? Direitos Emergentes Na Sociedade GolbalAnuário do Programa de Pós-Graduação em Direito da UFSM. Organizadores: Jerônimo Siqueira Tybusch, Luiz Ernani Bonesso de Araujo e Rosane Leal da Silva. Ijuí. 2013. 
HERMITTE, Marie-Angele. O acesso aos recursos biológicos panorama geral. Diversidade Biológica e conhecimentos tradicionais. Orgs. DIAS, Marcelo Varella; PLATIAU, Ana Flávia Barros. Belo Horizonte: Del Rey, 2004.

MARQUES, Marília Bernardes. Patentes farmacêuticas e acessibilidade aos medicamentos no Brasil. In: Hist. cienc. Saúde - Manguinhos vol.7 nº 1 Rio de Janeiro Mar./Jun 2000.

MATHIAS, Fernando. Conhecimentos Tradicionais Novos Rumos e Alternativas de Proteção. In: ISA. Conhecimentos tradicionais <http://pib.socioambiental.org/pt/c/direitos/temasrecentes/conhecimentos-tradicionais-e-biodiversidade>. Acesso em: 12 de mar. de 2017.

Ministério do Meio Ambiente. Convenção da diversidade biológica. Disponível em: < http://www.mma.gov.br/biodiversidade/convencao-da-diversidade-biologica>. Acesso em: 12 de mar. de 2017.

OST, François. A Natureza à Margem da Lei: A Ecologia à Prova do Direito. Lisboa: Instituto Piaget, 1997.

SANTILLI, Juliana. Socioambientalismo e novos direitos: proteção jurídica à diversidade biológica e cultural. São Paulo: Peirópolis, 2005.

. Conhecimentos tradicionais associados à biodiversidade: elementos para a construção de um regime jurídico sui generis de proteção. In. Diversidade Biológica e conhecimentos tradicionais. Orgs. DIAS, Marcelo Varella; PLATIAU, Ana Flávia Barros. Belo Horizonte: Del Rey, 2004.

SHIVA, Vandana. Biopirataria: a pilhagem da natureza e do conhecimento. Petrópolis: Vozes. 2001.

SONEGO, Elisabetha leal. Análise da Inconstitucionalidade de Patente Pipeline: Revalidação ou concessão originária? Disponível em: nov.

<http://www.unifra.br/eventos/sepe2012/Trabalhos/7187.pdf>. Acesso em: 12 de mar. de 2017.

TÁVORA, Fernando lagares. Comentários à lei n. 13.123, de 20 de maio de 2015: novo marco regulatório do uso da biodiversidade. Núcleo de estudos e pesquisas da consultoria legislativa. Textos para Discussão 184, out. 2015.

VELÁZQUEZ, Victor Huho Tejerina; OLIVEIRA, Michele Christina Souza Colla de. A Inconstitucionalidade das patentes Pipeline no Ordenamento Jurídico Brasileiro. Disponível em: <http://www.publicadireito.com.br/artigos/?cod=1 fe46a07a9ba5f05>. Acesso em: 09 dez. 2016.

VIEIRA, Vinicius Garcia. Direito da biodiversidade e América Latina: a questão da propriedade intelectual. Ijuí: Unijuí, 2012. 